\title{
DOES LEADERSHIP NEED EMOTIONAL INTELLIGENCE?
}

\author{
"in-press" \\ Leadership Quarterly \\ Theoretical and Practitioner Letters
}

\author{
Contributors \\ John Antonakis \\ Faculty of Business and Economics \\ University of Lausanne \\ Neal M. Ashkanasy \\ University of Queensland Business School \\ The University of Queensland \\ Marie T. Dasborough \\ Spears School of Business \\ Oklahoma State University
}




\title{
Does Leadership Need Emotional Intelligence?
}

\begin{abstract}
Interest in emotional intelligence has bloomed over the last few years. That it has become a standard concept in general and applied psychology, as well as in applied business settings, is indubitable. Is this popularity warranted? Casting a shadow over the concept of emotional intelligence are concerns about its meaningfulness and the construct and predictive validity of its various measures. The following series of letters explores various issues surrounding emotional intelligence and leadership including: whether emotional intelligence is theoretically needed for leadership, the types of emotional intelligence tests that may hold the most promise, methodological standards for testing whether emotional intelligence matters, evidence from the neuroscience literature on emotions and intelligence, and evidence regarding the links between leader emotional intelligence and follower outcomes.
\end{abstract}

Author-supplied keywords: emotional intelligence, intelligence, personality, leadership, neuroscience. 


\section{LETTER 1:}

Dear Neal and Marie:

It is a pleasure to have the opportunity to engage you in a debate about a construct dear to many, but whose foundations I--and a growing number of others--consider to be feeble. I suggested the title of our exchange because it can be interpreted in one of two ways: (a) to advance, does leadership as a science need "emotional intelligence" (EI)? (b) to succeed, do leaders need EI? Before providing you with a more developed response as to why I will answer "yes" and "no" to the above two questions respectively, as well as discuss measurement and predictive validity concerns surrounding EI, I would like to make a one thing clear. I was, and am to a certain degree, open to the idea of new conceptions of intelligence (Antonakis, Cianciolo, \& Sternberg, 2004). Yet, given the flimsy evidence, I have gone from pilgrim to skeptic. In the spirit of open inquiry, I hope that my letter will stimulate discussion on important issues surrounding EI so that the field of leadership advances, either pulling EI along the way or leaving it behind.

\section{Claims, or Reclaimations and Reclaims}

Although you and I are now sitting on different sides of this academic issue, I was happy to see that you (Jordan, Ashton-James, \& Ashkanasy, 2006) have recently tempered your position regarding the construct by explicitly questioning the hyperbolic claims made by some (e.g., Goleman, Boyatzis, \& McKee, 2002), who seem to care more about selling books than advancing science. That is, you show some skepticism too regarding whether EI predicts work success and leadership in particular. I took much pleasure from seeing you write that Goleman's “claims have done considerable harm to the field" (Jordan et al., p. 204)--an estimation that I share with you entirely. Furthermore, you distance yourselves from Goleman and Bar-On (Daus \& Ashkanasy, 2003), who have very broad definitions "trait" definitions of EI, and you have placed your bets on 
the Salovey and Mayer (1989-1999) "ability" model. I commend you for this bold move. Selfreported trait EI will not do the trick, particularly if researchers control for IQ and personality (see Antonakis 2003; 2004). Given that we agree on these points, I will refer mostly to the Salovey-Mayer ability model in my critique of EI. The Salovey-Mayer definition asserts that EI is an ability of sorts that is distinct from personality (though related somewhat to IQ, Ashkanasy \& Daus, 2005). This ability is composed of four branches: emotion perception, emotion facilitation, emotion understanding, and emotion management. I too think that this model might be the way to go, even though it is very disappointing to see that the meta-analytic correlation between the Salovey-Mayer MEIS ability scale of EI and performance outcomes was only .19 (Van Rooy \& Viswesvaran, 2004).

Evidently, the EI product has been badly designed. In the face of mounting evidence not boding well for EI, consumer defenders are filing "class-action suits" so to say (e.g., Conte, 2005; Locke, 2005; Matthews, Zeidner \& Roberts, 2002; Zaccaro \& Horn, 2003; Zeidner, Matthews, \& Roberts, 2004). I too recently suggested that given the sparse empirical evidence, it is unethical and unconscionable to use these measures in applied settings (i.e., for hiring, promotion, or retention, Antonakis, 2003, 2004). So, on one hand, I was encouraged to see you state that "management practitioners need to take care that they do not overemphasize the predictive value of emotional intelligence in workplace settings" (Jordan et al., p. 205). Yet on the other hand, you state there is a "logical tie between emotional intelligence and leadership," that "Research has substantiated this intuition," and that "the emerging empirical evidence supports the link between 
leadership ability (particularly transformational leadership ${ }^{1}$ ) and the abilities-based model of emotional intelligence" (Daus \& Ashkanasy, 2005, p. 459 \& p. 460).

These latter statements puzzle me. You took Goleman to school on his claims; then, without providing much methodologically defensible evidence published in peer reviewed journals, you suggest that EI matters for leadership (the evidence you cited in Daus \& Ashkanasy, 2005, includes two conference proceedings, a doctoral dissertation that shows that EI is irrelevant at top leader levels of organizations, and studies that are methodologically weak, as based on the criteria I use below). How then, can you still have so much faith in the power of EI, even suggesting that that emotional intelligence training for leadership is justifiable (Dasborough \& Ashkanasy, 2003)? I would be interested to learn more about your position and to review any recent methodologically-robust studies you are aware of that I may have overlooked.

\section{EI's Purpose: Helping to Advance Science by Refutation}

You apologize for the lack of empirical support because of the "infancy" of EI research (Jordan et al., 2006, p. 191). It is now close to 20 years since Salovey and Mayer (1989-1990) wrote their groundbreaking piece. With the correct instruments and careful measurement we can easily establish whether EI exists as it has been conceived and whether it predicts anything useful. Data showing the EI matters for leadership is nonexistant; either (a) EI researchers are using the wrong measures or the wrong methodology, or (b) EI does not matter for leadership.

At this point, I will get to the first question I posed in the beginning of my letter to you. It is an easy question to answer. To advance, does leadership as a science need EI? I answered yes, because to understand which individual-differences predict leadership effectiveness we have to, of course, identify correlates of leadership. We also must rule-out individual differences that do

\footnotetext{
${ }^{1}$ This claim is based on the result of one conference presentation, Daus and Harris [2003], which I could not locate. Based on the description of Daus and Ashkanasy, the sample consisted of students working on a class project; thus, its ecological validity is highly dubious. It is also unclear whether Daus and Harris controlled for IQ or personality.
} 
not correlate with leadership. Through theoretical deduction, intuition, observation or sometimes serendipity, scientists will come across constructs that could add predictive utility to their models. Scientists must be open-minded about all possibilities, including the possibility that a construct close to their hearts and one that is intuitively appealing might fail to predict what they would like it to predict. If constructs do not show any utility scientists ditch them and move on. This neverending process of inquiry serves science in good stead and advances knowledge.

Whether or not EI proves to be useful in the end is irrelevant. Although EI has not shown much utility for leadership_as I discuss below_leadership research is benefiting by knowing that EI might not matter. Thus, future research will move on and avoid the pitfalls of the past (by either improving the measurement models or dumping the construct). I believe that current notions of EI--assuming that they are correctly defined and measured--will continue to produce the disappointing results that they have done in the past; so something must change.

General mental ability (or IQ) is the single best predictor of work success, with metaanalytic correlations that are high (.51 -.62) that increase with job complexity; other metaanalyses show that the correlation between (a) IQ and objective measures of leader performance and that of (b) IQ and leader emergence is .33 and .50 respectively (refer to Antonakis, 2003; 2004 for cited references). These correlations are as good as they get in applied psychology. Furthermore, these correlations will not be easily displaced by other individual-difference measures (although established measures of personality do add some unique predictive variance).

The Van Rooy and Viswesvaran (2004) meta-analysis I cited earlier, which has been touted by EI aficionados to provide convincing evidence that EI matters for performance success indicated that EI failed to predict variance in performance measures beyond the variance predicted by $I Q$ (and the correlation between EI measures in general and various performance measures was only .24). Of course, work performance and leadership are not synonymous; 
however, an ability measure, which is supposed to be general, should be able to predict outcomes in a variety of performance domains, as does IQ. IQ is a very good predictor of work success, management performance, training success, and leadership; however, it is not a perfect predictor. Simply because the theoretical possibility is left open that other individual differences beyond IQ or established measures of personality might explain the remaining variance (a) does not mean that the residual variance is due to systematic differences that are measurable and if so that (b) that we will actually find these measures when controlling for IQ and personality. EI aficionados are much more sanguine about these possibilities than the data actually suggest. I am perplexed that you know there is a dearth of evidence showing that EI matters much for work success and leadership in particular, yet you state "The absence of empirical data to support a claim does not prevent the claim from being valid" (Jordan et al., 2006, p. 191). One cannot negate this assertion (which is not a claim, by the way--claims should follow data and not vice versa). By this logic any theoretical possibility thus becomes an irrefutable claim!

\section{EI Researchers Are Using the Wrong Measures or Wrong Methodologies}

Because of ignorance, or even convenience, some researchers do not test their theories appropriately and are far too quick to run through the streets screaming "eureka"! Some reviewers and editors too are to blame to a certain extent, because the do not judge validation studies appropriately. To test a theoretical framework appropriately, the following methodologically-appropriate steps usually apply: (1) Construct validity: are the measures associated with their constructs as theory would suggest a priori? (2) Criterion validity: do the constructs predict a practically-useful outcome (e.g., leadership)? (3) Discriminant validity: do the constructs measure something different from competing constructs (e.g., IQ, personality)? (4) 
Convergent validity: do tests measuring a similar construct correlate strongly with each other? ${ }^{2}$

(5) Incremental validity: The litmus test of validity—does EI predict practically-useful outcomes controlling for IQ (a full measure of crystallized and fluid ability) and personality (the big five, i.e., neuroticism, extraversion, openness, conscientiousness, and agreeability)?

Apart from demonstrating the above, for a study to be taken seriously by leadership scholars (in my experience, Steps 6 and 7 below are probably some of the reasons why studies get rejected from top journal like The Leadership Quarterly or Journal of Applied Psychology nowadays), in addition to demonstrating incremental validity, the study must also: (6) Avoid gathering leader self-reported measures of leadership, which are highly biased. (7) Obtain leadership measures from one source (e.g., subordinates, peers, bosses) and leader individual differences from another (e.g., leader IQ, EI, personality) to avoid problems associated with common-source/methods variance. (8) Use measures that were specifically designed to tap into EI. (9) Use practicing leaders in real-world contexts (the dynamics of social interaction and hence antecedents of success are not the same in student and real-world settings). (10) Have an acceptable sample size and also control for hierarchical nestings if pertinent (i.e., levels of analysis). I am not going through these steps because you need a capsule psychometrics lesson; I am using the above as a basis from which to judge research on EI to ensure that researchers do not make incorrect inferences or claims that are redundant.

\section{$\underline{\text { Are EI ability measures moribund? }}$}

In Antonakis (2004) I stated that I did not find even one study that was well designed (i.e., used the above steps for psychometric validation) and showed that EI predicts leadership to a practically-useful extent. Three years later, where are we? I would love to see just one strong

\footnotetext{
${ }^{2}$ Let us ignore step 4 above for the time being (given that we are dealing with the Salovey-Mayer model, which is unique - still, there are other ability/performance based measures of constructs related to EI (particularly emotion perception), for example measures of nonverbal decoding ability.
} 
study (that has applied the above steps) showing that EI mattes much for leadership. The venerable Salovey-Mayer measure cannot seem to get over Step 3 above. Apart from the studies I cited in Antonakis $(2003 ; 2004)--$ one of which showed that the Mayer Salovey Caruso Emotional Intelligence Test (MSCEIT) was almost entirely predicted by IQ, the big five, and gender (the multiple correlation was .81!, Schulte, Ree \& Carretta, 2004)--Roberts, Schulze, O'Brien MacCann, Reid, and Maul (2006) recently showed that the MSCEIT has serious problems with its construct, convergent, and discriminant validity. If EI cannot even get beyond Step 3 and 4 above, what hope is there for it to get to Step 5 and beyond? Not much, I regret to say.

In your latest review (Jordan et al., 2006), "gold standard" papers that you cite included the following: (a) Sosik \& Megerian [1996], who did not use established EI measures; (b) Rubin, Munz, and Bommer [2005], who used an ability measure of nonverbal decoding (and not of EI) and who did not control for all the big five measures nor for IQ (and Rubin et al. found a trivial correlation of .17 between nonverbal decoding ability and transformational leadership); (c) Lopes, Salovey, Coté, and Beers [2005], who used students (mean age of 21 years) and whose criterion measure was not leadership but "people skills"--and it is not clear from the measures used in this study whether these "people skills," apparently measuring interpersonal sensitivity and prosocial tendencies, actually correlate with leadership ability (in fact, Lopes et al. never mention the word "leader" or "leadership"). Lopes et al. found that after controlling both for the big five and IQ that the EI scores were only marginally related to the [probably irrelevant] outcome measure.

There we have it! After my reviews, you did not identify any well designed studies that show that EI matters for leadership. Perhaps something that will sway me has been published since your reviews--however, my search came up with naught. Something is wrong somewhere and this something is surely the measure to some extent, or maybe the methodology. 
Is the EI ability methodology off the mark?

One huge challenge facing the EI ability measures is the scoring method (Matthews et al., 2002; Zeidner et al., 2001). Briefly, EI researchers favor what can be termed "consensus" or “expert scoring. Unlike most IQ tests, which have clearly established objective answers, EI tests are calibrated based on experts' judgments or majority respondent ratings. For those items that are vignette-based and where respondents require to endorse the appropriateness of a response, the "closer" a particular respondent's answer is to the "correct" (i.e., the mean of the experts' score or the consensus score) answer the "more" EI the individual has. This approach to measurement essentially deals with differences scores.

It has been long known that difference scores suffer from unreliability, ambiguous interpretation, confounded effects, and untested constraints, thus resulting in potentially flawed findings (e.g., see Edwards, 1995). Better procedures exist to test congruence models, yet the entire EI community has overlooked this point. I would like to see what you think of the Edwards approach to using differences scores, which can be useful in a couple of ways. I will show you one way, useful for vignette-type performance measures (e.g., as included in the MSCEIT), where the question we examine is: does EI congruence (i.e., difference between a respondent's score on an item and that of the consensus or expert mean) depend on IQ? Here it is easy to test whether increasing IQ is associated with a smaller difference score. In this case, we cannot simply examine the direction and strength of the difference score but must use dummy variables to code those individuals who were overraters (e.g., those who respond higher than the "correct" response) or underraters (those who respond lower than the "correct" response). To know whether IQ predicts "higher" EI (i.e., an EI score that is closer to the correct score), one simply tests the interaction between the IQ score and the dummy variable (coded 0 for underraters and 1 for overraters) in the following regression: $Y_{E I}=a+\beta_{I Q}+\beta_{d u m m y}+\beta_{I Q * d u m m y}$ 
If the interaction is significant, a simple plot of the fitted model shows whether increasing congruence depends on IQ. That is, one regression line will be generated for overraters (whose responses are higher than the correct response) and one regression line for underraters (whose responses are lower than the correct response). The model will show that IQ predicts EI to the extent that these two regression lines converge towards the consensus (or expert) mean.

Edwards' methods for testing congruence models can be applied to EI scores as independent variables too, and can be used to evaluate more complex multivariate congruence models. To conclude here, I trust you see that all previous ability-based EI research based in part on vignette-type measures, including those that I cited, is now suspect because the form or the strength of the relationship between EI and other measure might not be what was reported.

\section{The "Curse of Emotion" Phenomenon?}

We are now back to square one and left to discuss my second major question: To succeed, do leaders need EI? Given the paucity of evidence, this question is purely theoretical. First, I believe that we agree that leadership is, in part, about managing emotions. To manage the emotions of others does one need to have an inordinately well-tuned EI? I vote no. Smarts will do. Leaders can easily affect the emotions of followers and upset them or make them happy by understanding simple condition-action scripts. These scripts are schemata (cognitive knowledge structures) reflecting procedural knowledge about events or situations, including social interactions, and they are learned from repeated exposition to events (Antonakis, 2003, 2004). An example script would be: If in situation A [i.e., a follower is distraught about a recent failure] then do action A1 [i.e., act kindly towards the follower]. Violating the script (i.e., what is considered as being appropriate or normative) by insulting the follower will obviously produce a bad outcome. Vicarious or direct experience in condition-action outcomes allows one to see patterns and to abstract, and learning about condition-action scripts depends on one's general 
ability to learn (Antonakis, 2004). What's the difference between recognizing emotional condition-action scripts versus other forms of scripts? Unless one is a "clinical case" I cannot see why learning processes regarding emotional recognition and abstraction are different from other cognitive processes.

What makes leaders good depends on how intelligent they are (important for many processes, e.g., identifying weaknesses in the status go, formulating strategic and tactical plans, communicating vision) and whether they have the right personality characteristics, that is, high extraversion and openness, and low neuroticism (important for being assertive, gregarious, energetic, progressive, calm, etc.) and how they use these individual differences to mobilize their followers. Being sensitive enough to act on and manage the emotions of others in an appropriate way depends on IQ. However, being overtly sensitive to the emotional states of others or not wanting to act appropriately depends on personality. For example, neurotic types will be hostile and panicky (which is not useful for leadership in business settings). Although meta-analyses show that agreeability is unrelated to leadership it is related to EI. Those who are agreeable will likely be ineffective because these individuals will not be assertive enough on contentious issues, and will be "bogged down" by the emotional states of others (because they are too empathetic).

Theoretically, the more sensitive to the emotional states of others leaders are the more difficult it may become for those leaders to ignore those states and act in a way that is needed to reify the organizational vision (and possibly cause further emotional grief to followers). This "emotional curse" will also be prevalent if one is unduly sensitive to one's own emotional states. In a way, this phenomenon is similar to the "curse of knowledge" phenomenon, and more specifically to the "illusion of transparency" phenomenon (see Gilovich, Savitsky, \& Husted, 1998). Because of a simple anchoring effect, the more individuals are aware of their own emotional states, the more they believe others are aware of these states, and the more they will be 
bogged down by these emotional states (and probably more so if they care much about what others think of them). Note that there are very easy ways to deal with and manage this awareness, suggesting that this skill is not an innate ability, but learnable (Savitsky \& Gilovich, 2003). The skill is thus not an intelligence but dependent on intelligence (i.e., one's ability to learn).

I have come to the end of my missive and look forward to reading and responding to your reply. To summarize: EI trait models should be jettisoned and ability models should be tested more completely (using correct methodologies); there is very little evidence, using EI measures demonstrating that EI matters much for leadership when using methodologically-defensible procedures and controlling for established individual-difference measures; finally, apart from methodological shortcomings, it is possible that EI is not predictive of leadership because, quite simply, EI may be more of a curse than a blessing.

Sincerely,

John Antonakis 


\section{References}

Antonakis, J. (2003). Why "emotional intelligence" does not predict leadership effectiveness. The International Journal of Organizational Analysis, 11, 355-361.

Antonakis, J. (2004). On why "emotional intelligence" will not predict leadership effectiveness beyond IQ or the "big five": An extension and rejoinder. Organizational Analysis, 12, $171-182$.

Antonakis, J., Cianciolo, A. T. \& Sternberg, R. J. (2004). Leadership: Past, present, and future. In J. Antonakis, A. T. Cianciolo, \& R. J. Sternberg (Eds.). The nature of leadership, (pp. 315). Thousand Oaks: Sage Publications.

Ashkanasy, N. M., \& Daus, C. S. (2005). Rumors of the death of emotional intelligence in organizational behavior are vastly exaggerated. Journal of Organizational Behavior, 26, 441-452.

Conte, J. M. (2005). A review and critique of emotional intelligence measures. Journal of Organizational Behavior, 26, 433-440.

Dasborough, M. T., \& Ashkanasy, N. M. (2003). Is emotional intelligence training for leaders justified? Australian Journal of Psychology, 55 (supplement), 120-121.

Daus, C. S., \& Ashkanasy, N. M. (2003). Will the real emotional intelligence please stand up? The Industrial and Organizational Psychologist, 41, 69-72

Edwards, J. R. (1995). Alternatives to difference scores as dependent variables in the study of congruence in organizational research. Organizational Behavior and Human Decision Processes, 64, 307-324.

Gilovich, T., Savitsky, K., Medvec, V. H. (1998). The illusion of transparency: Biased assessments of others' ability to read one's emotional states. Journal of Personality and Social Psychology, 75, 332-346. 
Goleman, D., Boyatzis, R., \& McKee, A. (2002). Primal leadership. Boston: HBS Press.

Jordan, P. J., Ashton-James, C. E., \& Ashkanasy, N. M. (2006). Evaluating the claims: Emotional intelligence in the workplace. In Kevin R. Murphy (ed). A critique of emotional intelligence (pp. 189-210). Mahwah, NJ: Lawrence Erlbaum.

Locke E. A. (2005). Why emotional intelligence is an invalid concept. Journal of Organizational Behavior, 26, 425-431.

Matthews, G., Zeidner, M., \& Roberts, R. D. (2002). Emotional Intelligence: Science and Myth. Cambridge, MA: MIT Press.

Roberts, R. D., Schulze, R., O'Brien, K., MacCann, C., Reid, J., \& Maul, A. (2006). Exploring the validity of the Mayer-Salovey-Caruso emotional intelligence test (MSCEIT) with established emotions measures, Emotion, 6, 663-669

Salovey, P., \& Mayer, J. D. (1989-1990). Emotional intelligence. Imagination, Cognition and Personality, 9, 185-211.

Savitsky, K., \& Gilovich, T. (2003). The illusion of transparency and the alleviation of speech anxiety. Journal of Experimental Social Psychology, 39, 618-625.

Schulte, M. J., Ree, M. J., \& Carretta, T. R. (2004). Emotional intelligence: Not much more than g and personality. Personality and Individual Differences, 37, 1059-1068.

Van Rooy, V. D., \& Viswesvaran, C. (2004). Emotional intelligence: A meta-analytic investigation of predictive validity and nomological net. Journal of Vocational Behavior, $65,71-95$.

Zaccaro, S. J., \& Horn, Z. N. J. (2003). Leadership theory and practice: Fostering an effective symbiosis. Leadership Quarterly, 14, 769-806.

Zeidner, M., Matthews, G., \& Roberts, R. D. (2004). Emotional intelligence in the workplace: A critical review. Applied Psychology: An International Review, 53, 371-399. 


\section{LETTER 2:}

Dear John

Thank you for your informative and well-argued letter. We appreciate that you are very emotionally committed to your point of view, and that you believe that researchers in organizational behavior and leadership may be barking up the wrong tree then it comes to emotional intelligence. In our response to your letter we deal with five specific topic areas: (1) epistemological issues; (2) measurement issues; (3) leadership, emotion, and IQ; (4) research issues, and finally, (5) your assertions about the "curse of emotion."

\section{Kuhn or Popper?}

At the outset, we would like to address the epistemological basis of your case. In fact, the line of argument you take in your letter is fraught with danger. You seem to be trying to say that, if a certain field of scientific inquiry is seen to be flawed in some respect, researchers should steer clear of it. In essence, your line of reasoning would seem to be aligned with the Kuhnian idea of normal vs. revolutionary science, where paradigms are vigorously defended by their adherents until the pressure for change becomes so overbearing that a revolutionary "paradigm shift" occurs. Well, that's your right.

We prefer to adopt a scientific framework based on Karl Popper's principles, where scientists seek to test theories rigorously and objectively, and are prepared to discard old theories which are shown to fail these tests. Thus, instead of seeking to advance science in a series of (rare) revolutionary advances, Popperian scientists engage in a continuous process of revolution: testing and discarding theories that fail to measure up based on the empirical data (Shareef, 2007). In the instance of leadership research, a Popperian framework involves openness to new ideas (such as the role of emotional intelligence in leadership), which should then be the basis for new propositions to be tested using valid empirical data. 
A key tenet of the Popperian framework of scientific advancement is that conclusions should not be drawn from a failure to find results in the early stages of theory testing. Here, there is a whole literature on the futility of "accepting the null." Accepting the null is problematical because it is difficult to tell if null findings are attributable to a real lack of the effect under investigation, or because of too much error (e.g., tests lack power or are insufficiently developed). In this respect, you chide us for appealing to the "infancy" of emotional intelligence research, when it is "close to 20 years since Salovey and Mayer (1990) wrote their groundbreaking piece.” Well, we are sorry, but this is still early years for any theory, as Jordan, Ashton-James, and Ashkanasy (2006) describe. The theory of intellectual intelligence is now over 100 years old, and is still in a state of turmoil, controversy, and continuing development (Sternberg, 2002).

You also take us to task for the statement "The absence of empirical data to support a claim does not prevent the claim from being valid" (Jordan et al., 2006, p. 191), stating, "One cannot negate this assertion (which is not a claim, by the way--claims should follow data and not vice versa). By this logic any theoretical possibility thus becomes an irrefutable claim!" Goodness! What can we say but we strongly disagree! "Claims should follow data and not vice versa?" We thought this was the very basis of deductive science. This is that, by using a process of theoretical deduction, scientists develop testable hypotheses (claims) and then collect data to test them. Of course, this is also the basis of the Popperian framework. There are whole disciplines (e.g., theoretical physics, theoretical economics) where theoretical scientists do nothing but develop claims. And they sometimes must wait many years until the technology emerges to test their theories (claims). Aspects of Einstein's theories of relativity, for example, are still awaiting the development of technology to test them. Yet, no-one would claim that Einstein's theories are nothing but "irrefutable claims." In the instance of emotional intelligence, as we explained in the foregoing paragraph and just like testing Einstein's theory of relativity, 
measurement development is ongoing with a view to developing future tests to check out theoretical propositions (or claims).

\section{Measurement Issues: Emotional Intelligence and IQ}

You spend a lot of your letter discussing the shortcomings of measuring emotional intelligence. Frankly, we do not take issue with you in this respect. There are many shortcomings in measures of emotional intelligence (as there are in measures of IQ). But this is also the point we made earlier, and which also applies equally in all areas of psychological measurement and assessment (Mischel, 1968). The shortcomings in current-day measures of emotional intelligence are well known and, as you point out, have been debated and discussed at length in the literature, as they should be. But this is no reason for scientists to throw up their hands in despair. Indeed, it should be a motivation to continue to forge ahead to develop new, more reliable, more valid, and more relevant measures.

A particular problem underlying your whole line of argument seems to be that you appear to be wedded - Kuhnian style - to the idea of a unified concept of IQ. Thus, like most critics of emotional intelligence who take this view (e.g., see Waterhouse, 2006), you reject the idea that modern conceptions of intelligence have moved on from the unified " $\mathrm{g}$ " concept. Even your mentor, Robert Sternberg, as you know is a strong advocate for multiple conceptualizations of intelligence.

As for differentiating emotional and cognitive aspects of intelligence, I suggest you read Antonio Damasio's (1994) book, Descartes' Error. Take special note of Damsio's story about Elliot, a patient with a ventromedial prefrontal tumor that affected his ability to perceive emotions, but who consistently scored a high IQ. Yet Elliott was quite incapable of managing his affairs, or even of making the most basic decisions about his personal life. Elliott had a high IQ, but absolutely no emotional intelligence because of his brain impairment. Since 1994, moreover, 
an overwhelming volume of evidence, especially in neuroscience, has accumulated in support of the idea that emotional awareness and understanding is separate from intellectual intelligence, and these abilities directly impact human decision-making capabilities (e.g., see Naqvi, Shiv, \& Bechara, 2006).

You see, the point is not which measure of emotional intelligence we use. The point (which, as you note, we already agree upon) is that emotions play an important role in leadership. If this is so, then, as with other dimensions of human thought, feelings, and behavior, there are going to be individual differences.

\section{Leadership: Role of Emotion, and IQ}

In our third topic area, we address your comments about leadership, emotion, and IQ.

First, let us look at leadership and emotion. The ideas of leadership involving emotions of followers and emotional abilities being associated with effective leadership have been around since the early trait theories of leadership (see George, 2000). You even admit the connection in your discussion of "the curse of emotion" (more on this later). Recently, Dasborough (2006) has empirically demonstrated that leaders evoke emotional responses in employees in workplace settings. Moreover, it is now widely accepted that leadership is an emotion-laden process, and a leader who can manage his/her own emotions and have empathy for others will be more effective in the workplace.

Moreover, we do not really need to repeat why leadership could be enhanced by emotional intelligence. George (2000) has already explained how emotions play a central role in the leadership process, and how emotional intelligence contributes to the effectiveness of leaders. In her article, George emphasizes the connection between the emotional abilities and effective leadership behaviors, and identifies five essential elements for leadership effectiveness:

(1) developing collective goals and objectives; (2) instilling in others a sense of appreciation and 
importance of work; (3) generating and maintaining enthusiasm, confidence, optimism, cooperation, and trust; (4) encouraging flexibility in decision making and change; and (5) establishing and maintaining meaningful identity for the organization. Each of these elements involves emotional aspects, where leaders high on emotional intelligence may be better at achieving these outcomes.

We also recognize that, in some situations, leader emotional intelligence may be more important than in others, especially situations where cognitive resources are constrained; for example, in highly stressful work situations (Salas, Driskell, \& Hughs, 1996). Indeed, it could well be that the "very disappointing" meta-analytic correlation between the Salovey-Mayer MEIS ability scale of emotional intelligence and performance outcomes (Van Rooy \& Viswesvaran, 2004) that you cite was a result of the different contexts in which performance was assessed. Perhaps some empirical studies included performance in situations that lacked social interaction, or had few emotional demands.

We also remind you also that Van Rooy and Viswesvaran (2004) were not referring to leadership in their study. They focused instead on general performance, such as job performance and academic success. Obviously, the further away we get from relationship type outcomes, such as the relationship between a leader and follower, the less relevant emotions and emotional intelligence become. Of course general intelligence explains more of the variance in outcomes such as academic success! Emotions are not a key component of academic performance, which is largely cognitive in nature. This is precisely what Jordan and Troth (2004) found: IQ is key in cognitive tasks, emotional intelligence is key in social situations.

Our point is that relationship approaches to leadership are inherently emotional. In particular we (Dasborough \& Ashkanasy, 2002) have already argued that leader-member exchange relationship quality is enhanced through emotional intelligence of leaders. Zhou and 
George (2003) have argued along similar lines that emotional intelligence can enhance leadership within team settings. As a corollary of this, we argue that research on emotional intelligence and leadership effectiveness needs to be focused on those approaches to leadership that involve emotional elements. Transformational leadership and charismatic leadership both involve inspirational motivation and idealized influence, which are emotional for the followers. Further, Prati, Douglas, Ferris, Ammeter, and Buckley (2003) provide sound theoretical arguments about the role of emotional intelligence and the proposed relationship between leader EI and motivation, charismatic leadership, and transformational leadership.

Turning now to discussion of the role of IQ in leadership, we actually agree with your point that general intelligence can be an important factor in leadership. Of course it is. Our point is that there is also evidence to suggest that, just as emotional intelligence effects can be contextdetermined, general intelligence can become less important for the leader in certain situational contexts. In this respect, Judge, Colbert, and Ilies (2004) enlisted principles of cognitive resource theory to make the case that general intelligence is a predictor of leadership effectiveness only when leaders are in low stress situations. Under high stress conditions, on the other hand, cognitive resources are more difficult to access, so the leader's cognitive intelligence becomes less salient, and s/he is forced to rely on other, non-cognitive, abilities. Here, emotional intelligence enables leaders to deal with stressful environments, and to focus their attention back onto the task at hand (Ashkanasy, Ashton-James, \& Jordan, 2004). Once the leader has dealt with the stressful situation, general intelligence can resume the spotlight.

Finally in this section, we ask you to be clear about what exactly constitutes "effective leadership." In other words, the issues you raise may not lie with emotional intelligence at all. It may be that the construct of leadership effectiveness can itself be viewed in different ways. Some definitions of effective leadership may be more amenable to study in terms of IQ, while others 
may be more appropriately viewed though the lens of emotional intelligence. House and Aditya (1997), for example, in a review of leadership models, concluded that effective leaders are those who best facilitate achievement of the group's goals. Here, we acknowledge that general intelligence is important for achieving task goals that require intellectual acumen. If, on the other hand, leadership is viewed it terms of a relationship that develops between leaders and their followers (Uhl-Bein, 2006), then it would follow that emotional intelligence may be the more relevant criterion for effectiveness.

\section{Research Issues}

Like other Kuhnian critics of emotional intelligence research (e.g., Locke, 2005; Waterhouse, 2006), you seem to "to mix together popular claims, scientific claims, and claims on Web sites and then (dismiss) the area without a systematic or thorough review of the actual published scientific literature” (Cherniss, Extein, Goleman, \& Weissberg, 2006, p. 239). For instance, you criticize Daus and Ashkanasy (2005) on the basis that the research they cited was not rigorous enough, yet these authors acknowledged that the research they described was still in its early years, and that a continuing research effort was needed to confirm the encouraging results to date.

We also recognize that some of the research to date that has purported to support emotional intelligence has been flawed and/or inconclusive. But so also is some of the research that appears to support a more negative assessment of emotional intelligence. For example, you cited the Schulte, Ree, and Carretta (2004) study that found the Mayer Salovey Caruso Emotional Intelligence Test (MSCEIT) to be predicted by IQ, the big five personality variables, and gender. But this study involved a small sample of students and failed to look at the different branches of emotional intelligence identified by Mayer and Salovey (1997). In other words, just as you accuse us of over-reliance on isolated and flawed research; it seems to us that you are happy to go 
down this very same path when it suits your objectives. On the other hand, empirical studies today are tackling the validity issues surrounding emotional intelligence, and some of this work is appearing in the best peer-reviewed scholarly journals in our discipline (e.g. Administrative Science Quarterly, Journal of Applied Psychology). In other words, problems are being investigated, and new ideas are being explored.

Consequently, rather than taking a purely reactionary approach to your points, and consistent with our earlier argument about Popperian epistemology, we suggest that it is not appropriate that this stage to dump emotional intelligence research. On the contrary, we need to take a more proactive stance, and to see what needs to be done to advance further our understanding of leadership and its relationship to emotional behavior and intelligence. We remind you that, despite their ostensibly pessimistic findings in relation to emotional intelligence and performance, Van Rooy and Viswesvaran (2004) still concluded their study by asserting, "EI is a construct that is definitely worthy of future research" (p.86).

In this case, we agree with you that scholars must use better methods to explore the nomological network surrounding emotional intelligence. For example, Uhl-Bein (2006), in arguing for a relational theory of leadership, called for future research to explore how various types of emotion are involved in leadership relationship development and in leadership emergence. A relational perspective would explore how emotion is constructed and spread in leader-follower interactions that take place in ongoing local-cultural-historical contexts. We suggest that this perspective is one in which emotional intelligence could play a central role. We note further that, in many studies of emotional intelligence (e.g., see Daus \& Ashkanasy, 2005), the most interesting findings have been connected to individual branches of emotional intelligence rather than overall scores. We suggest that scholars would do well to focus in on 
these separate abilities. This may reduce some of the overlapping variance with personality and intelligence.

\section{The “Curse of Emotion:” A New Research Topic?}

Finally, we come your assertion about the "curse of emotion." What were you thinking? Your whole line of argument collapses on this point. You see, if it is in fact true that effective leadership can be hamstrung by over-awareness of emotions, then this would seem to us to be a perfectly reasonable proposition to test. Is this what you are advocating? But then, how do you intend to measure leaders' emotional sensitivity in the first instance? Since Mayer and Salovey (1997) define emotion intelligence in terms of four "branches" (ability to perceive emotions, to use emotions to facilitate thinking, to understand emotions, and to manage emotions in self and others), it would seem to us to be eminently sensible for researchers to consider the MSCEIT to measure this variable.

The point here is that that the Mayer and Salovey (1997) model of emotional intelligence actually does include management of emotion as its fourth branch. In earlier experimental work, Dasborough (2004) found that high emotional intelligence individuals (as assessed using the MSCEIT ability based test), reported less intense emotional responses to leader-follower interactions. While high emotionally intelligent individuals may have had more awareness of their emotional states, and better understanding of why they were experiencing those emotions, they were also able to manage them better than those low on emotional intelligence. In effect, and referring again to principles of cognitive resource theory, high emotional intelligence individuals chose to conserve their scarce cognitive resources and did not become distracted by intense emotions. Here it was the low emotional intelligence individuals who were unable to deal with the emotions they encountered. Again, we recommend examining each of the abilities separately to determine their unique contributions to leadership effectiveness. While they are 
correlated abilities subsumed under the broader construct of EI, the skills associated with the management of emotions may prove to be of utmost importance for leaders. It seems that the "curse of emotion" may in fact be an excellent topic for emotional intelligence research after all!

\section{Concluding Comments}

In conclusion, we have made the point here that science is best served by a Popperian approach to discovery, where scientists maintain an open mind and test theories rigorously, discarding theories that fail the test, and adopting and testing new theories as they emerge. This is in contrast to the Kuhnian approach, where the status quo is defended vigorously, and new theories adopted only when the old become completely untenable. We then pointed out that we do not disagree with you on the measurement issues to which you refer. Measurement issues beset all branches of psychology, including IQ. Despite what you say, emotional intelligence is still a young concept in comparison to IQ, and research on development and improvement of measures is ongoing. We point out in particular that research has now established beyond doubt that emotional and intellectual intelligence are differentiable concepts. Damasio's (1994) patient Elliott had a high IQ, but no emotional intelligence. A further issue is that some definitions of effective leadership focus on cognitive abilities, while others - which we describe as "relational leadership" (Uhl-Bien, 2006) - are more amenable to an emotion-focused perspective. In this respect, we do acknowledge that IQ can be important, but it is not sufficient to account for many aspects of leadership, especially those involving social relationships and stressful situations. We agree with some of your arguments that emotional intelligence research in general tends to be of poor quality. We argue that researchers need to take a more proactive stance, using new and better methods to investigate exciting new ideas, including the roles of the different branches of emotional intelligence proposed by Mayer and Salovey (1997). And finally, we address your reference to the "curse of emotion," noting that high emotional intelligence leaders are not only 
more perceptive of emotions, they are also better at managing emotions, suggesting a new field for emotional intelligence research.

So you see, rather than just closing the book on the basis of the difficulties we are encountering in the early years of construct development, we instead urge scholars of leadership to continue researching this fascinating and potentially useful construct. This is what researchers do, John. Scientists don't just give up because some of the early evidence is flimsy and others question and criticize their work. They seek new, unexplored and exciting directions. It's great to be a part of this endeavor. We hope that you will see our point, and that you will rejoin the quest.

Sincerely,

Neal M. Ashkanasy

and

Marie T. Dasborough 


\section{References}

Ashkanasy, N. M., Ashton-James, C. E., \& Jordan, P. J. (2004). Performance impacts of appraisal and coping with stress in workplace settings: The role of affect and emotional intelligence. In P. Perrewé \& D. Ganster (Eds.), Research in occupational stress and wellbeing, volume 3: Emotional and psychological processes and positive intervention strategies (pp. 1-43). Oxford, UK: Elsevier/JAI Press.

Cherniss, C., Extein, M., Goleman, D., \& Weissberg, R. P. (2006). Emotional intelligence: What does the research really indicate? Educational Psychologist, 41, 239-245.

Damasio, A. R. (1994). Descartes' error: Emotion, reason, and the human brain. New York: Avon Books.

Dasborough, M. T. \& Ashkanasy, N. M. (2002). Emotion and attribution of intentionality in leader-member relationships. The Leadership Quarterly, 13, 615-634.

Dasborough, M. T. (2004, August). Follower emotional responses to perceptions of leadership: The moderating role of emotional intelligence. Paper presented at the Annual Meetings of the Academy of Management, New Orleans, Louisiana, USA.

Dasborough, M. T. (2006). Cognitive asymmetry in employee emotional reactions to leadership behaviors. The Leadership Quarterly, 17, 163-178.

Daus, C. S., \& Ashkanasy, N. M. (2003). Will the real emotional intelligence please stand up? The Industrial and Organizational Psychologist, 41, 69-72

George, J. M. (2000). Emotions and leadership: The role of emotional intelligence. Human Relations, 53, 1027-1055.

House, R. J., \& Aditya, R. N. (1997). The social scientific study of leadership: Quo vadis? Journal of Management, 23, 409-473 
Jordan, P. J., Ashton-James, C. E., \& Ashkanasy, N. M. (2006). Evaluating the claims: Emotional intelligence in the workplace. In Kevin R. Murphy (ed). A critique of emotional intelligence: What are the problems and how can they be fixed? (pp. 189-210). Mahwah, NJ: Lawrence Erlbaum.

Jordan, P. J., \& Troth, A. C. (2004). Managing emotions during team problem solving: Emotional intelligence and conflict resolution. Human Performance, 17, 195-218.

Judge, T., Colbert, A. E., \& Ilies, R. (2004). Intelligence and leadership: A quantitative review and test of theoretical propositions. Journal of Applied Psychology, 89, 542-552.

Locke E. A. (2005). Why emotional intelligence is an invalid concept. Journal of Organizational Behavior, 26, 425-431.

Mayer, J. D., \& Salovey, P. (1997). What is emotional intelligence? In P. Salovey \& D. J. Sluyter (Eds.) Emotional development and emotional intelligence: Educational implications (pp. 3-31). New York: Basic Books.

Mischel, W. (1968). Personality and assessment. New York: Wiley.

Naqvi, N., Shiv, B., \& Bechara, A. (2006). The role of emotion in decision making: A cognitive neuroscience perspective. Current Directions in Psychological Science, 15, 260-264.

Prati, L. M., Douglas, C., Ferris, G. R, Ammeter, A. P., \& Buckley, M. R. (2003). Emotional intelligence, leadership effectiveness, and team outcomes. International Journal of Organizational Analysis, 11, 21-40.

Salas, E., Driskell, J. E. \& Hughs, S. (1996). The study of human stress and performance. In J. E. Driskell \& E. Salas (Eds.) Stress and human performance (pp. 1-46). Manwah, NJ: Lawrence Erlbaum Associates.

Salovey, P., \& Mayer, J. D. (1990). Emotional intelligence. Imagination, Cognition and Personality, 9, 185-211. 
Schulte, M. J., Ree, M. J., \& Carretta, T. R. (2004). Emotional intelligence: Not much more than g and personality. Personality and Individual Differences, 37, 1059-1068.

Shareef, R. (2007). Want better business theories? Maybe Karl Popper has the answer. Academy of Management Learning \& Education, 6, 272-280.

Sternberg, R. J. (2002). The psychology of intelligence. Intelligence, 30, 482-483.

Uhl-Bien, M. (2006). Relational leadership theory: Exploring the social processes of leadership and organizing. The Leadership Quarterly, 17, 654-676.

Van Rooy, V. D., \& Viswesvaran, C. (2004). Emotional intelligence: A meta-analytic investigation of predictive validity and nomological net. Journal of Vocational Behavior, $65,71-95$

Waterhouse, L. (2006). Multiple intelligences, the Mozart effect, and emotional intelligence: A critical review. Educational Psychologist, 41, 207-225

Zhou, J. \& George, J. M. (2003). Awakening employee creativity: The role of leader emotional intelligence. The Leadership Quarterly, 14, 545-568. 


\section{LETTER 3}

Dear Neal and Marie:

I enjoyed reading your letter and found it interesting and challenging. Let me summarize where I think we agree: (1) validation studies should be rigorously designed; (2) there is no evidence for the predictive validity of EI for leadership (i.e., neither you nor I could locate one article, using the criteria for validation I listed, showing EI to matter); (3) if there is something to EI, it is ability-type tests that hold promise; (4) whether EI matters for leadership is a theoretical question; and (5) emotions are important for leadership and decision-making. I will come back to some of these points later. Below I respond to your major comments and discuss some interesting findings, some from the neurosciences literature. I focus on the latter because you incorrectly used it to prop up EI. I conclude, again, with bleak a perspective for current EI models.

\section{"Truth is what stands the test of experience" (attributed to Albert Einstein)}

In your response you stated that "A key tenet of the Popperian framework of scientific advancement is that conclusions should not be drawn from a failure to find results in the early stages of theory testing" (p. xxx). I did not know that Popper said that. What I know Popper (1963) for is his position that a theory (a set of hypotheses that purport to explain a phenomenon) must be falsifiable; it must make specific conjectures (hypotheses, propositions) that are testable. Thereafter, the theory can only tentatively establish itself when it has been subjected to failed attempts to refute it. As a result of the possibility of future falsification of the theory, it can never be proven. If a theory is refuted, it must be abandoned. That is where EI, in its current forms, is.

Unless a theory has been vigorously tested one should not make strong claims about it (“claims" from Latin means "to cry out, call, proclaim, declare aloud", Oxford English Dictionary) — the theory is still in the realm of the hypothetical. You used the term "claim" and "hypothesis" interchangeably stating "scientists develop testable hypotheses (claims) and then 
collect data to test them" (p. xxx). You also said "The absence of empirical data to support a claim [hypothesis] does not prevent the claim [hypothesis] from being valid" (Jordan et al., 2006, p. 191). I grant you the possibility and retort: "As I get older, the flying spaghetti monster increases my belief that EI does not matter for leadership." Should I bruit it about that the absence of empirical data to support my claim does not prevent the claim from being valid? Twenty years from now gauges might be developed to provide support for my conjecture. My claim is thus irrefutable. I hope you see that claims should be made sparingly and follow data/facts. We should proclaim facts and truths and be modest with conjectures. When the data fall in place, by all means turn up the volume.

You also stated that like Einstein's theories, EI has not yet been properly tested. We cannot pronounce verdicts about its validity because it is still a young theory. As scientists devised methods to test Einstein's propositions, his predictions held up so you believe there is still hope for EI. Did you know that Einstein's prediction, made in 1915, that light is bent by gravitational fields was confirmed as early as 1919 ? Should we not have seen some sparkle from EI in a domain that is infinitesimally simpler? There is weak evidence to support EI's viability and lots of evidence to show that it does not predict leadership. EI does not have the beauty, elegance, and precision of the theory of relativity; EI does not have strong theoretical foundations (and thus has little hope to work in practice). EI has been falsified. EI researchers should abandon their construct or go back to the drawing board and rethink it, leaving all options open.

\section{Two intelligences or one? A myth in the making}

You repeat a myth, propagated by Goleman et al. (2002) who stated "Studies of neurological patients with damaged prefrontal-limbic circuitry confirm that their cognitive capacities may remain intact, while their emotional intelligence abilities are impaired. This neurological fact clearly separates these competencies from purely cognitive abilities like intelligence" (p. 29). You 
said that because of a lesion to his ventromedial (orbitofrontal) prefrontal cortex (situated in the frontal lobes) "Elliott had a high IQ, but absolutely no emotional intelligence" (p. xxx). Apart from the obvious limitation of attempting to determine anything from a sample of one, Elliot was never given a test of EI per se. Also, patients with such lesions fail on many tasks that have nothing to do with socio-emotional phenomena; basically, they fail in decision-making, whether in personal, interpersonal, or financial settings (Naqvi et al., 2006). Indeed, the flagship test to ascertain emotional decision-making deficits is the Iowa Gambling Task, where players chose cards from four decks and try to maximize their gains based on feedback they receive on wins/losses from the cards drawn ${ }^{3}$ - no EI here.

Your statement, "Obviously, the further away we get from relationship type outcomes, such as the relationship between a leader and follower, the less relevant emotions . . . become," actually flies in the face of current findings in neuroscience. Neuroscience shows that emotions matter for many types of decision making; thus, if the EI construct is a general construct it should predict performance in a variety of domains. It does not when we control for IQ, as the Van Rooy and Viswesvaran (2004) meta-analysis showed. Also, the two studies you cite (Jordan \& Troth, 2004; Offermann et al., 2004) showing that "IQ is key in cognitive tasks, emotional intelligence is key

\footnotetext{
${ }^{3}$ This exercise was devised by Bechara to simulate a real decision-making task. On successive trials, subjects select cards from four decks with the goal of maximizing wins. Two of the decks (the "bad" decks) provide high immediate rewards but higher future losses (and result in a net loss if consistently selected). The other two decks (the "good" decks) provide smaller initial rewards; however, future losses are less severe (in proportion to the wins). Choosing from the good decks maximizes wins in the long-run (see Bechara \& Damasio, 2005). This exercise is particularly useful for showing how emotions matter for decision making given that in such a task, emotions (i.e., feeling/intuition) are needed to guide the player's decision making (given that demands on attention and information are large). Results consistently show that individuals with damage to the frontal lobes are oblivious how their actions might be linked to future consequences and these individuals focus on immediate/short-term prospects by drawing more cards from the bad decks. The link between their actions and brain function is evident after several draws from the decks. Unlike normal controls who learn (by "feel") to avoid the bad decks, brain-damaged players do not exhibit any physiological (i.e., emotional) signaling mechanisms prior to making a choice from a bad deck. Other tasks exist to show deficits in decision making (e.g., Rogers Decision-Making Task and the Delay Discounting Procedure, see Bechara \& Damasio, 2005). None of these tasks involve judgment of social or emotional situations.
} 
in social situations" (p. xxx) used self-report EI measures (the second study used measures based on the Goleman model!). Furthermore, these studies did not control for personality or IQ. In the neurosciences literature there are now many studies showing how lesions affect performance in a number of domains. At this time there is no study that has actually examined EI performance (or how EI predicts performance) of neurological and normal patients (controlling for IQ, of course). Thus, your and Goleman's oft-repeated generalization is myth, and attempts to provide specious support for two types of intelligence: emotional and cognitive. We have one integrated brain, one mind that decides, and one intelligence. This mind requires both emotional and non-emotional processes and feedback systems to function. Simply because we process information about emotions and other things does not mean we have different intelligences.

\section{What a feeling! Keep believing}

Our ability to find patterns and to predict future events, whether in emotional or non-emotional realms depends mostly on fluid intelligence. Also, taking decisions requires biological "signaling" mechanisms, somatic markers, that give us a positive or negative anticipatory "feeling" about how we should decide based on previously-experienced good or bad outcomes (and how we felt afterwards). This emotional signaling process is usually measured physiologically via anticipatory (i.e., pre-decision) skin conductance responses during a decisionmaking task. These feelings, which originate in the ventromedial prefrontal cortex, are a decision heuristic that work with other parts of the brain (e.g., amygdala, Bechara \& Damasio, 2005) and use cognitive processes like working memory (Hinson, Jameson, \& Whitney, 2002; Wallis, 2007). Incidentally, working memory is strongly related to IQ (Oberauer, Shulze, Wilhelm, \& Süss, 2005).

Emotions help us to make effective decisions; that is certain. Does that mean that using emotions effectively or intelligently is emotional intelligence? No, it is not. It is simply the natural use of 
emotions for normal adaptive functioning; it occurs implicitly and it is automatized. As I said in my first letter to you: "Unless one is a 'clinical case', I cannot see why learning processes regarding emotional recognition and abstraction are different from other cognitive processes" (p. xxx). By "clinical case" I meant individuals with severe psychological or neurological impairments. Thus, normal individuals should exhibit adequate performance on decisions requiring emotions. Indeed Bechara, Damasio and colleagues never predicted individual differences in normal controls; normal controls always perform very well on the gambling task. The variance in performance in controls is usually small, which does not leave much to predict in the normal patients (particularly if we were to control for IQ). Of course, as the task becomes more demanding and complex, IQ and associated cognitive processes will play a bigger role.

\section{Gee whiz: It looks like $g$ !}

Studies that "established" that IQ remains intact when individuals sustain damage to the prefrontal cortex (includes the ventromedial area) are very limited because they may not have adequately measured fluid intelligence (see Wood \& Liossi, 2007). Also, testing patients in laboratory setting with simplified and structured tasks does not sufficiently tax executive functions (Duncan, Emslie, \& Williams, 1996, p. 296). The reason why many patients with prefrontal lesions lost friends and family, became financially ruined, or could not hold a job was not because their EI was damaged, but probably because they lost the real stuff, IQ (in addition to a lack of somatic signals) was damaged. Fluid ability $\left(g_{f}\right)$ reflects ability to learn, mental speed and flexibility. It is not knowledge dependent and does not reflect previously-acquired knowledge. Thus, $g_{f}$ should be used to measure potential changes in intelligence after brain damage (Duncan et al., 1996).

Wood \& Liossi, (2007) found that both fluid and crystallized ability were low (i.e., mean was 88.76) in 118 patients with damage to the frontal lobes, as was their performance on tests of 
executive functioning. Note, IQ predicted performance on these tests, just as it does for normal individuals (see Obonsawin, et al., 2002). Similarly, Duncan et al. (1996) (see experiment 4) showed that patients with brain injury in the frontal lobes had $g_{f}$ scores that were significantly lower (between 9- 14 points) compared to a control group and another brain damaged group. Because these two studies had small samples and included patients with damage in rather broad areas, take look at current studies that used precise brain-scanning methods (e.g., fMRI or Voxelbased morphometry etc.) showing that brain regions included in the ventromedial area consistently correlate with IQ (Brodmann areas 10, 11, 47 in particular, Jung \& Haier, 2007; see also Colom, Jung, \& Haier, 2006; Frangou, Chitins, \& Williams, 2004; Narr et al., 2007). So much for the "Elliott area" reflecting EI! Judgment of causality or deductive logic also resides in the orbitofrontal cortex (Fonlupt 2003; Houdé et al., 2001). Important to note is that although IQ areas are distributed across the whole brain, interactions exist between regions (e.g., prefrontal and parietal areas, Jung \& Haier, 2007), suggesting a unified " $g$ theory" of intelligence.

\section{Who's stressing about IQ?}

You cite the meta-analysis of Judge et al. (2004) to support the notion that general intelligence predicts leadership effectiveness only when leaders are in low stress situations. Judge et al. only synthesized studies using dichotomized data (high and low stress situations). Unless the data came from an experimental setting, stress should be scored as a continuous variable and the following regression should be estimated: $Y_{\text {leader perf. }}=a+\beta_{I Q}+\beta_{\text {stress }}+\beta_{I Q * \text { stress. There are }}$ established meta-analytic techniques to synthesize interaction effects of this nature (Kanetkar, Evans, Everell, Irving, \& Millman, 1995). Fiedler and Link (1995) actually looked at the IQstress interaction (in 13 samples)—alas, this data was not included in Judge et al. In most of the models Fiedler and Link tested, both IQ and stress had positive slopes and the interaction was positive too (see Table 6.3). This result suggests exactly the opposite to what you said (and 
dispels another myth in the making). The relation of IQ to leader performance is stronger in high stress than in low stress situations. Referring specifically to leader performance in situations with interpersonal stress, Fiedler (1995) noted: "Our studies do not support the hypothesis . . that intelligence tests are not useful in predicting leadership performance in complex or intellectually demanding tasks. On the contrary ... intelligence tests seem to predict performance somewhat better in intellectually demanding and complex tasks, than in simple or routine ones" (p. 52).

\section{On branches, samples, and buffers}

You critique the Schulte et al. (2004) study I cited showing that the variance in the MSCEIT was almost wholly predicted by IQ, the big five, and gender. You then suggested that I cited flawed research because this study (a) used students, (b) had a small sample, and (c) used a global EI factor and not the four EI branches. Using students is fine for construct validation (as it is fine to use lesion patients to determine if the prefrontal cortex affects information processing). However, it is not fine to use students for determining whether EI matters for leadership (because the context is not ecologically valid, refer to the next section). Next, Schulte et al. had a sample of 102, which I would call respectable. Finally, the four-branch model of the MSCEIT is not viable (Gignac, 2005). If you think that using a global EI factor is limited, why then do you use a onefactor model in your research (Ashkanasy \& Dasborough, 2003; Dasborough, 2004)?

Next, you refer to the Dasborough (2004) study—which used students and did not control for IQ or personality—as evidence for the utility of emotional management for followership. I interpreted these results differently. The results you report clearly show that individuals with low EI had a more positive response to a sincere leader (and would theoretically comply with such a leader). Low EI individuals also had a more negative response to a manipulative leader (and would thus be less likely to comply with such a leader). This behavior seems intelligent, right? High EI followers had "less intense" responses to these leaders, that is, they had a less positive 
response to a sincere leader and a less negative response to a manipulative leader. These results suggest that managers should hire low EI followers.

\section{The curse continues}

You stated that "it is now widely accepted that . . . a leader who can manage his/her emotions and have empathy for others will be more effective in the workplace" (p. xxx). Two issues are important to note here. First, it is well established that emotional stability, as measured by personality tests does correlate with leadership in business settings (Judge, Bono, Ilies, \& Gerhardt, 2002). We have no evidence that emotional management, as measured by EI ability tests, matters. Second, agreeability (which includes empathy), as measured by personality tests is unrelated to leadership in business, government or military settings (Judge et al., 2002); however, it is positively related to leadership in student samples (this finding demonstrates that the correlates of leadership are not the same in student and business samples, as I stated previously). The evidence overwhelmingly suggests that individuals who are agreeable or high in affiliation do not make good leaders (probably because they are unable to take a stand on difficulty matters, are submissive, and put individual interests ahead of organizational interests). If empathy is related to EI, as you suggest, then here is more evidence that EI does not matter for leadership.

\section{Conclusion}

EI has captivated the public and some well-meaning researchers. Web of Science finds over 100 published articles and reviews with the terms "emotional intelligence" and "leadership"; the majority of the studies happily assume or "demonstrate" that EI matters for leadership. Google finds almost 1 million pages with the terms "emotional intelligence" and "leader/leadership." Unfortunately, practice and voodoo science is running way ahead of rigorous research. To advance our scientific boundaries, editors and reviewers must take their responsibilities seriously and use appropriate standards (e.g., the 10 steps I listed in Letter 1) to judge papers submitted for 
review. Not enough papers are being sent back to their issuers marked "NSF" (non-sufficient facts). More "NSF" papers will perhaps stimulate the rigorous theory-based empirical research that perhaps will vindicate you one day.

To conclude, I think your defense of EI does not fly. I may be wrong and leave the possibility open that future versions of EI might one day show their worth. I hope you pay attention to the evidence and leave open the possibility that EI might one day go the way of the Raphus Cucullatus, the dodo bird, destined for extinction.

I have enjoyed my role as your adversarial collaborator and hope that our discipline will benefit from our exchange.

Sincerely,

John Antonakis 


\section{REFERENCES}

Bechara, A., \& Damasio, H. (2005). The somatic marker hypothesis: A neural theory of economic decision. Games and Economic Behavior, 52, 336-372.

Duncan, J., \& Emslie, H., \& Williams, P. (1996). Intelligence and the frontal lobe: The organization of goal-directed behavior. Cognitive Psychology, 30, 257-303.

Fiedler, F. E., \& Link. T. G. (1994). Leader intelligence, interpersonal stress, and task performance. In R. J. Sternberg \& R. K. Wagner (Eds.), Mind in context: Interactional perspectives on human intelligence (pp. 152-167). Cambridge: University of Cambridge.

Fonlupt, P. (2003). Perception and judgment of physical causality involve different brain structures. Cognitive Brain Research, 17, 248-254.

Frangou, S., Chitins, X., \& Williams, S. C. R. (2004). Mapping IQ and gray matter density in healthy young people. NeuroImage, 23, 800-805.

Gignac, G. E. (2005). Evaluating the MSCEIT V2.0 via CFA: Comment on Mayer et al. (2003). Emotion, 5, 233-235.

Hinson, J. M., Jameson, T. L., \& Whitney, P. (2002). Somatic markers, working memory, and decision making. Cognitive, Affective, \& Behavioral Neuroscience, 2, 341-353.

Houdé, O., et al. (2001). Access to deductive logic depends on a right ventromedial prefrontal area devoted to emotion and feeling: Evidence from a training program. NeuroImage, 14, 1486-1492.

Judge, T. A., Bono, J. E., Ilies, R., \& Gerhardt, M. W. (2002). Personality and Leadership: A Qualitative and Quantitative Review. Journal of Applied Psychology, 87, 765-780.

Kanetkar, V., Evans, M. G., Everell, S. A., Irving, D., \& Millman, Z. (1995). The effect of scale changes on meta-analysis of multiplicative and main effects models. Educational and Psychological Measurement, 55, 206-224. 
Narr, K. L. et al. (2007). Relationship between IQ and regional cortical gray matter thickness in healthy adults. Cerebral Cortex, 17, 2163-2171.

Obonsawin, M. C., Crawford, J. R., Page, J., Chalmers, P., Cochrane, R., \& Low, G. (2002). Performance on tests of frontal lobe function reflect general intellectual ability. Neuropsychologia, 40, 970-977.

Oberauer, K., Shulze, R., Wilhelm, O., \& Süss, H-M. (2005). Working memory and intelligence-Their correlation and their relation: Comment on Ackerman, Beier, and Boyle (2005). Psychological Bulletin, 131, 61-65.

Popper, K. R. (1963). Conjectures and refutations: The growth of scientific knowledge. New York: Harper Torchbooks.

Wallis, J. D. (2007). Orbitofrontal cortex and its contribution to decision-making. Annual Review of Neuroscience, 30, 31-56.

Wood, R. L., \& Liossi, C. (2007). The relationship between general intellectual ability and performance on ecologically valid executive tests in a severe brain injury sample. Journal of the International Neurophsychological Society, 13, 90-98. 


\section{LETTER 4:}

\section{Dear John}

Thank you for your reply to our letter. As ours is the final letter in the series, it would seem appropriate to review our journey to date. In your original letter, you opened by making the point that emotional intelligence lacked empirical support, especially in leadership research, and that researchers should instead use IQ as the valid reliable predictor of leader behavior and outcomes. You then went on to elucidate ten criteria that must be met to establish construct validity in leadership research, stating that these are "the basis for which to judge research on EI." Following this, you stated that you could not find a single study on EI and leadership that met these criteria, and concluded that even the most accepted "gold standard" measures of emotional intelligence are flawed. In your final point, you agreed that leaders do need to manage emotions, but this is a function of a leader's IQ, not emotional intelligence. And you also introduced the idea of a "curse of emotion," whereby leaders who are oversensitive to emotions will become "bogged down" and unable to discharge their leadership roles properly.

In our reply to your opening letter, we first addressed the epistemological underpinnings of your case, and suggested that you seemed to be following the Kuhnerian approach where existing paradigms are defended to the last. We argued for a Popperian approach, which involves openness to new ideas that can be tested empirically. In particular, we maintained that it is too early to conclude that that emotional intelligence is ineffectual, and that conclusions should not be drawn from "hypothesizing the null." We agreed that present-day measures of emotional intelligence could be improved, and cited neurobiological evidence that emotional awareness and understanding are distinct from traditional IQ. In our next point, we argued that "relationship approaches to leadership are inherently emotional" and that the impact of emotional and general 
intelligence in leadership is context-dependent; some leadership situations demand high IQ, while others require high EI. Our final point was that, just as the literature in favor of the proposition that emotional intelligence is important for leadership is mixed, so is the literature you cite. We urged scholars to continue to pursue "new, unexplored and exciting directions", such as how emotional intelligence may enhance specific leadership behaviors.

In your reply to our letter, you opened by stating four points upon which we agreed (more on this later), then castigated us for making "strong claims" in the absence of empirical support, concluding that "EI has been falsified." In your next point, you assert that humans have only "one intelligence" (emphasis in original). You then (strangely in view of your earlier emphatic pronouncement) differentiate between fluid and crystalline intelligence, and cite neurobiological evidence to support the idea that fluid intelligence involves use of emotions; concluding that this is still not emotional intelligence. In the following sections, you reinterpret various studies (including one of ours) to refute our contentions that emotional intelligence is a multi-faceted construct that may benefit leadership. You then reintroduced the "curse of emotion," implying that empathetic leaders can be ineffective. In your conclusion, you dismiss as "voodoo research" the accumulating peer-reviewed literature that does not support your point of view, and conclude that emotional intelligence will "go the way of the ... dodo bird."

\section{The points we agree upon and points of disagreement}

So let's revisit the points of agreement you identified: (1) Need for rigorous research. Yes, but this is a motherhood statement. (2) No evidence for the predictive validity of EI for leadership. Well, yes, but only if you strictly apply your ten criteria. (3) In contrast to self report EI measures, ability measures of emotional intelligence hold out the best hope. Yes, we agree here, although we also concur that the current tests can be improved. (4) The importance of EI for 
leadership effectiveness is a theoretical question. Well, yes, and so ...? (5) Emotions are important for leadership and decision-making. Yes, we agree on this point.

As you can see, we actually do agree on most points, but we believe that one of them, Point 2, warrants more careful scrutiny. We agree with you here, but only on the proviso that the ten criteria apply. The simple fact is that, virtually without exception, all research in our field is flawed in some way or another. This is also the case in every field of research in the social sciences. If these ten criteria were applied strictly across the board, nothing would be published. For example, Sara Rynes (personal communication, March 21, 2008) relates that, at the beginning of her term as AMJ Editor, she and her team were rejecting at a rate that was far too high ever to fill the pages of the journal, and that she had to ask her team to "loosen up" to address this situation. Schmidt and Hunter (2002) refer in this respect to the "myth of the perfect study," and conclude that, "In fact, there are no perfect studies" (p. 51).

As we stated in our first reply, the criteria for scientific acceptance of a construct should be peer-review. It's the best we have; whereby our esteemed colleagues are responsible for policing the quality of empirical research on EI and leadership. As the British Academy (2007) recently concluded, "peer review remains an essential, if imperfect, practice for the humanities and social sciences" (p. 12). As scholars, we simply cannot go around dismissing the peerreviewed work of our colleagues as "voodoo science." Nor can we condescendingly refer to our colleagues as "well meaning." As we pointed out earlier in this exchange, some of EI research is appearing in the most stringent and highly rated journals in our field (e.g. AMR, AMJ, ASQ, JAP, LQ, JOB). So while we agree with you that no EI studies meet all the strict criteria you set out, we point to the accumulating bulk of research in the most highly regarded peer-reviewed journals in our field that is supportive of emotional intelligence in general, and its role in leadership in particular. 
Finally on this point, we note that, in our own roles as journal editors and editorial board members, we actively encourage high quality research; and we trust that other editors and reviewers do the same. In recent years in fact, both of us have rejected many manuscripts on EI and leadership because of poor construct definition and discriminant validity. Although we are advocates of EI research, we too, wish to promote high quality research on EI and leadership, continuously striving for more valid and reliable measures.

\section{One intelligence or multi-intelligence?}

In your reply, you go to great lengths to make the point that there is only "one intelligence." Nonetheless, and while we respect your opinion, this is a debate that has been going on ever since Gardner (1983) first introduced the idea of multiple intelligences, and will probably still be going on when we are all long gone (see Davidson \& Downing, 2000, for an overview of the issue). If you like to believe that how people solve spatial and verbal puzzles is good enough to explain leader behavior, we think we will just have to agree to disagree on this point.

On the more fundamental issue of the neurobiological basis of intelligence, why should we (and the readers of this letter exchange) regard your interpretations of the literature as being in any way definitive? To illustrate, you make the point that the brain is a totally integrated unit. While to some extent this is indeed so, it's just not a matter of "believing." We refer you in particular to LeDoux's (1995) seminal work in identifying the role of the amygdale in rats. LeDoux's rats had their cortexes removed, yet were able to detect and to react to a threat. More recent research (some of which you cite) has verified the existence of complex neural channels of emotion in the mammalian brain (e.g., see Bernston et al., 2007, for a recent review), suggesting that its workings may be too complex to be understood in terms of ' $g$.' We suggest that all three of us had better leave this discussion to the experts in the field. 
One of the more confusing aspects of your argument is that, after maintaining that there is "one intelligence," you then blithely go on to discuss two intelligences: crystalline and fluid. Aside from the obvious contradiction, the discussion of the role of emotion in fluid intelligence left us, well, flabbergasted. You appear to be making the point that fluid intelligence is some sort of substitute for emotional intelligence. It's as if emotional intelligence is a myth, but fluid intelligence doing the same sort of thing is OK. Sorry, but this line of reasoning simply does not cut it. Indeed, in a recent study, Côté and Miners (2006) found that cognitive and emotional intelligence interacted, such that EI compensated for the effect of low IQ on task performance. While this study did was not related to leaders specifically, the results do seem to suggest the opposite of your idea relating to fluid intelligence; that emotional intelligence may in fact substitute for cognitive intelligence. Again, the point here is that we still need to do a lot more research before we understand what is going on here. Asking scholars to cease following up on a promising line of research like this is not going to help.

\section{A valid assessment of EI}

We call for scholars new to the field of EI research to read carefully the recent article by Mayer, Roberts, and Barsade (2008) before embarking on empirical investigations. Mayer and his colleagues review the emotional intelligence literature over the last 18 years, with particular attention to conceptualization and validity of EI measures, and provide an objective overview concerning reliability and validity. Also, like the three of us, they call for higher quality empirical research, and specifically research that meets criteria set out in the Standards for Educational and Psychological Testing (JCS, 1999). In fact, it is these standards that apply for development of measures, rather than any notion of meeting the ten criteria you set out in your first letter. Importantly, Mayer et al. (2008), referring to empirical research on the ability based model of EI, conclude that "together they (ability measures of EI) exhibit test validity as a group" 
(p.527, emphasis added). As they also note, "EI is a predictor of significant outcomes across diverse samples in a number of real-world domains" (p. 527). Still, as you point out, and as we discussed earlier in this reply, there is no one single study on EI that has established its construct validity unequivocally. Thus, we urge scholars to use the criteria presented in the Standards. In this respect, we concur with Mayer and his associates that there are three broad categories particularly relevant to EI validation and research: (a) adequate test design relative to theories of EI, (b) the structure of EI measurement (to tell us whether EI is one thing or many things), and (c) test relationships with key benchmarks. All of these issues must be addressed within empirical investigations for the field to advance. Moreover, and despite your skepticism, real progress is being made on all three of these fronts.

\section{Back to the "curse of emotion"}

You return to the "curse of emotion" theme raised in your initial letter. As we already pointed out, this idea seems to undercut your whole line of reasoning. We reiterate our earlier point that, if your suppositions are theoretically tenable, then why not put them to the test? We will not dispute with you how we or you or others have interpreted the results of our findings. You can make your own call. The test is in research yet to come. In addition, you address this question by referring to "EI" as if it were a valid concept - which would seem once again to contradict everything you have been arguing for in these letters.

\section{To conclude: Popper or bust}

In conclusion to this exchange, we would like to add a further point upon which we believe we all agree. This is that researchers need to continue to develop and to study emotions and in particular their role in leadership. Moreover, you even acknowledge in your conclusion the possibility that "future versions of EI may one day show their worth." Of course, we agree with this. You then go on to ask us to "leave open the possibility that EI might one day go the 
way of the ... dodo bird." Here again, we agree. Despite all your negative assertions regarding EI, we are scientists, and believe in the Popperian principles of empirical testing designed to refute hypotheses. You state that we should not be making outrageous claims for emotional intelligence. But it's not us who are making these claims; indeed, we specifically reject them (see Ashkanasy \& Daus, 2005; Jordan et al, 2006; Jordan, Ashkanasy, \& Daus, 2008).

Also as you acknowledge, empirical evidence on emotional intelligence is building. It's not perfect - as you have so forcefully pointed out - but a great many dedicated, educated, and intelligent scholars are working in this field with a view to increasing our understanding of social phenomena such as leadership. It would be such a shame if this work were to be prematurely aborted just because some early findings have been open to criticism or alternative explanation. We are sure you would be the last to disagree with this position.

Finally, and similar to Mayer et al. (2008), we conclude that, although there are problems with the measurement of EI (and some conceptualizations of it), the emerging field of EI research has served to highlight the important role of emotions in social relationships. In particular, the contribution we focus on is the role of emotions in leadership, and the need for leaders to be aware of, and to attempt to manage emotions in themselves and in their followers. We are open to the possibility that one day EI may go the way of the dodo bird; but we are confident that this will not be the case for some time. Considering that the EI construct has made its way into the latest Annual Reviews of Psychology (Mayer et al., 2008) as a viable and important construct, it appears, despite the best efforts of its detractors, EI research is going to be with us into the foreseeable future. We thank you for inviting us to join you in this exchange. We have learned much from our participation, and we trust you have done likewise.

Sincerely

Neal M. Ashkanasy and Marie T. Dasborough. 


\section{References}

Berntson, G. G., Bechara, A., Damasio, H., Tranel, D., \& Cacioppo, J. T. (2007). Amygdala contribution to selective dimensions of emotion. Social Cognitive and Affective Neuroscience, 2, 123-129.

British Academy. (2007). Peer review: The challenges for the humanities and social sciences. London, UK: The British Academy.

Côté, S., \& Miners, C. T. H. (2006). Emotional intelligence, cognitive intelligence, and job performance. Administrative Science Quarterly, 51, 1-28.

Davidson, J. E., \& Downing, C. L. (2000). Contemporary models of intelligence (pp. 34-52). In R. J. Sternberg (Ed.), Handbook of intelligence. New York: Cambridge University Press.

Gardner, H. (1983). Frames of mind. New York: Basic Books.

LeDoux, J. E. (1995). In search of an emotional system in the brain: Leaping from fear to emotion and consciousness. In M. S. Gazzaniga (Ed.), The Cognitive Neurosciences (pp. 1049-1061). Cambridge, MA: MIT Press.

Joint Committee on Standards (JCS). (1999). Standards for educational and psychological testing. Washington DC: American Educational Research Association.

Jordan, P. J., Ashkanasy, N. M., \& Daus, C. S. (2008). Emotional intelligence: Rhetoric or reality? In S. Cartwright \& C. L. Cooper (Eds.) The Oxford Handbook of Personnel Psychology (pp. 37-58). Oxford, UK: Oxford University Press.

Mayer, J. D., Roberts, R. D., \& Barsade, S. G. (2008). Human abilities: Emotional intelligence. Annual Review of Psychology, 59, 507-536.

Schmidt, F. L., \& Hunter, J. E. (2002). Meta-analysis. In N. Anderson, D. S. Ones, H, K. Sinangil, \& C. Viswesvaran. (Eds.), Handbook of work and organizational psychology (pp. 51-70). London: Sage Publications. 